\title{
Impaired right ventricular lusitropy is associated with ventilatory inefficiency in pulmonary arterial hypertension
}

\author{
Khodr Tello ${ }^{1}$, Antonia Dalmer ${ }^{1}$, Rebecca Vanderpool ${ }^{2}$, Hossein A. Ghofrani ${ }^{1,3,4}$, \\ Robert Naeije ${ }^{5}$, Fritz Roller ${ }^{6}$, Werner Seeger (1) ${ }^{1}$, Daniel Dumitrescu ${ }^{7}$, \\ Natascha Sommer ${ }^{1}$, Anne Brunst ${ }^{1}$, Henning Gall $\mathbb{0}^{1}$ and Manuel J. Richter ${ }^{1}$ \\ Affiliations: ${ }^{1}$ Dept of Internal Medicine, Justus-Liebig-University Giessen, Universities of Giessen and \\ Marburg Lung Center (UGMLC), Member of the German Center for Lung Research (DZL), Giessen, Germany. \\ ${ }^{2}$ University of Arizona, Tucson, AZ, USA. ${ }^{3}$ Dept of Pneumology, Kerckhoff Heart, Rheuma and Thoracic Center, \\ Bad Nauheim, Germany. ${ }^{4}$ Dept of Medicine, Imperial College London, London, UK. ${ }^{5}$ Erasme University \\ Hospital, Brussels, Belgium. ${ }^{6}$ Dept of Radiology, Justus-Liebig-University Giessen, Universities of Giessen and \\ Marburg Lung Center (UGMLC), Member of the German Center for Lung Research (DZL), Giessen, Germany. \\ ${ }^{7}$ Dept of Cardiology, Heart and Diabetes Center NRW, Ruhr University Bochum, Bad Oeynhausen, Germany.
}

Correspondence: Khodr Tello, Dept of Internal Medicine, Justus-Liebig-University Giessen, Klinikstrasse 32, 35392 Giessen, Germany. E-mail: Khodr.Tellodinnere.med.uni-giessen.de

@ERSpublications

Right ventricular diastolic stiffness and afterload (pressure-volume loop measurement) are associated with ventilatory inefficiency during exercise and may contribute to dyspnoea via increased chemosensitivity in pulmonary arterial hypertension http://bit.ly/30lLy9t

Cite this article as: Tello $\mathrm{K}$, Dalmer A, Vanderpool $\mathrm{R}$, et al. Impaired right ventricular lusitropy is associated with ventilatory inefficiency in pulmonary arterial hypertension. Eur Respir J 2019; 54: 1900342 [https://doi.org/10.1183/13993003.00342-2019].

ABSTRACT Cardiopulmonary exercise testing (CPET) is an important tool for assessing functional capacity and prognosis in pulmonary arterial hypertension (PAH). However, the associations of CPET parameters with the adaptation of right ventricular (RV) function to afterload remain incompletely understood.

In this study, 37 patients with PAH (idiopathic in 31 cases) underwent single-beat pressure-volume loop measurements of RV end-systolic elastance (Ees), arterial elastance (Ea) and diastolic elastance (Eed). Pulmonary arterial stiffness was assessed by magnetic resonance imaging. The results were correlated to CPET variables. The predictive relevance of RV function parameters for clinically relevant ventilatory inefficiency, defined as minute ventilation/carbon dioxide production $\left(V^{\prime}{ }_{E} / V^{\prime} \mathrm{CO}_{2}\right)$ slope $>48$, was evaluated using logistic regression analysis.

The median (interquartile range) of the $V^{\prime}{ }_{\mathrm{E}} / V^{\prime} \mathrm{CO}_{2}$ slope was $42(32-52)$ and the $V^{\prime}{ }_{\mathrm{E}} / V^{\prime} \mathrm{CO}_{2}$ nadir was 40 (31-44). The mean $\pm \mathrm{SD}$ of peak end-tidal carbon dioxide tension $\left(P_{\mathrm{ETCO}_{2}}\right)$ was $23 \pm 8 \mathrm{mmHg}$. Ea, Eed and parameters reflecting pulmonary arterial stiffness (capacitance and distensibility) correlated with the $V_{\mathrm{E}}^{\prime} / V^{\prime} \mathrm{CO}_{2}$ slope, $V_{\mathrm{E}}^{\prime} / V^{\prime} \mathrm{CO}_{2}$ nadir, $P_{\mathrm{ETCO}_{2}}$ and peak oxygen pulse. RV Ees and RV-arterial coupling as assessed by the Ees/Ea ratio showed no correlations with CPET parameters. Ea (univariate OR 7.28, 95\% CI 1.20-44.04) and Eed (univariate OR 2.21, 95\% CI 0.93-5.26) were significantly associated with ventilatory inefficiency $(\mathrm{p}<0.10)$.

Our data suggest that impaired RV lusitropy and increased afterload are associated with ventilatory inefficiency in PAH.

This article has supplementary material available from erj.ersjournals.com

Individual participant data that underlie the results reported in this article, after de-identification, may be shared upon reasonable request, subject to approval from the Right Heart I study committee.

Received: 18 Feb 2019 | Accepted after revision: 15 Aug 2019

Copyright OERS 2019 


\section{Introduction}

Shortness of breath dominates the symptomatology of pulmonary arterial hypertension (PAH). Much of it is related to an excess of ventilation $\left(V_{\mathrm{E}}^{\prime}\right)$ at any level of metabolic rate, as defined by an elevated $V_{\mathrm{E}}^{\prime}$ /carbon dioxide output $\left(V^{\prime} \mathrm{CO}_{2}\right)$ slope during a cardiopulmonary exercise test (CPET) $[1,2]$. An increase in $V^{\prime}{ }_{\mathrm{E}} / V^{\prime} \mathrm{CO}_{2}$ slope is an important predictor of outcome in patients with $\mathrm{PAH}[3,4]$ and evaluating the $V_{\mathrm{E}}^{\prime} / V^{\prime} \mathrm{CO}_{2}$ slope has therefore been recommended as part of the risk assessment in these patients [5]. However, the pathophysiology of $\mathrm{PAH}$ is currently understood to depend on the adaptation of right ventricular (RV) function to afterload [6-8]. Thus, symptomatology and survival in these patients is critically dependent on the adequacy of RV-pulmonary arterial (PA) coupling, as defined by a preserved ratio of end-systolic elastance (Ees) to arterial elastance (Ea) at a normally low end-diastolic elastance (Eed) [6-8]. Although the $V_{\mathrm{E}}^{\prime} / V^{\prime} \mathrm{CO}_{2}$ slope has previously shown associations with other parameters reflecting RV afterload and function in heart failure $[9,10]$, the relationship of wasted ventilation to Ees/Ea and Eed in PAH remains incompletely understood.

We therefore investigated RV function by invasive determination of RV pressure-volume loops to calculate Ees, Ea and Eed and related the results to $V^{\prime}{ }_{\mathrm{E}} / V^{\prime} \mathrm{CO}_{2}$ slope or nadir and other CPET parameters previously reported to be of relevance, such as peak oxygen uptake $\left(V^{\prime} \mathrm{O}_{2}\right)$ and $\mathrm{O}_{2}$ pulse [11]. We also measured PA compliance as an important determinant of RV afterload by magnetic resonance imaging (MRI) [12].

\section{Methods}

\section{Study design and patients}

For the current analysis, we included consecutive patients with $\mathrm{PAH}$ who were prospectively enrolled into the Right Heart I study (NCT03403868) and the Giessen Pulmonary Hypertension Registry [13] between January 2016 and April 2019. A subset of the patients had also been included in previously published analyses from the Right Heart I study [14-17]. The patients were diagnosed according to current recommendations [5], and each diagnosis was assessed by a multidisciplinary board (including pulmonary physicians and radiologists) before enrolment. All patients underwent CPET, MRI and pressure-volume/ Swan-Ganz catheterisation. PAH therapies were administered based on clinical grounds and best standard of care. B-type natriuretic peptide (BNP) was measured with a fully automated, two-site sandwich immunoassay (ADVIA Centaur BNP Test; Siemens Healthineers, Erlangen, Germany). Diffusion capacity of the lung for carbon monoxide $\left(D_{\mathrm{LCO}}\right)$ was measured by the single-breath technique [18]. All participating patients gave written informed consent for enrolment into the Right Heart I study. The investigation conformed to the principles of the Declaration of Helsinki and was approved by the ethics committee of the Faculty of Medicine at the University of Giessen (approval no. 108/15).

\section{Cardiopulmonary exercise testing}

All patients underwent symptom-limited incremental CPET (Vmax $229^{\circledR}$ system; Carefusion ${ }^{\circledR}$, now part of Vyaire $^{\mathrm{TM}}$ Medical, Yorba Linda, CA, USA) using a cycle ergometer in a semi-supine position and wearing a face mask. After an initial baseline measurement without exercise for $2 \mathrm{~min}$, exercise was initiated at a work rate of $10-30 \mathrm{~W}$, which was increased by $10-30 \mathrm{~W}$ every $1-2 \mathrm{~min}$ using a stepwise protocol as published previously [19]. Blood gases were analysed at rest and maximal exercise (from the hyperaemic ear lobe); heart rate was continuously monitored and a noninvasive blood pressure measurement was performed every $2 \mathrm{~min}$. Peak oxygen uptake $\left(V^{\prime} \mathrm{O}_{2}\right)$ was defined as the $V^{\prime} \mathrm{O}_{2}$ measured during the last $30 \mathrm{~s}$ of peak exercise. The respiratory exchange ratio (RER) was calculated as $V_{\mathrm{CO}_{2}}^{\prime} / V^{\prime} \mathrm{O}_{2}$, and $\mathrm{O}_{2}$ pulse as $V^{\prime} \mathrm{O}_{2}$ /heart rate. The ventilatory equivalents for carbon dioxide were calculated by dividing $V_{\mathrm{E}}^{\prime}$ (corrected for equipment external dead space) by $V^{\prime} \mathrm{CO}_{2} \cdot V^{\prime}{ }_{\mathrm{E}} / V^{\prime} \mathrm{CO}_{2}$ slopes were measured between warm up and anaerobic threshold. The nadir of $V^{\prime}{ }_{\mathrm{E}} / V^{\prime} \mathrm{CO}_{2}$ was assessed as described previously [20]. Arterial carbon dioxide tension $\left(P_{\mathrm{aCO}}\right)$ to end-tidal carbon dioxide tension $\left(P_{\mathrm{ETCO}_{2}}\right)$ carbon dioxide gradient $\left(P_{(\mathrm{a}-\mathrm{ET}) \mathrm{CO}_{2}}\right)$ was measured at rest and during exercise [19].

\section{Magnetic resonance imaging}

Imaging was performed with the Avanto 1.5 Tesla scanner system (Siemens Healthineers; gradient strength and slew rate: SQ-Engine $\left(45 \mathrm{mT} \cdot \mathrm{m}^{-1}\right.$ at $\left.\left.200 \mathrm{~T} \cdot \mathrm{m}^{-1} \cdot \mathrm{s}^{-1}\right)\right)$. Stiffness, distensibility and capacitance of the pulmonary arteries were measured as described in detail previously [12].

\section{Right heart catheterisation}

Resting right heart catheterisation was performed as described previously [21]. Pressure values were continuously assessed. Cardiac index was measured using the direct or indirect Fick method as available. Pulmonary vascular resistance (PVR) was calculated as (mean pulmonary arterial pressure (mPAP)pulmonary arterial wedge pressure)/cardiac output [5]. 
Pressure-volume catheterisation

Pressure-volume catheterisation was performed and pressure-volume loops were generated as described previously [14]. Ees was calculated using the single-beat method for the right ventricle, and Ea was calculated as end-systolic pressure/stroke volume [22]. RV-PA coupling was calculated as Ees/Ea. A diastolic stiffness factor $\beta$ was calculated as described previously by a nonlinear fit of diastolic pressurevolume coordinates as $\mathrm{p}=\alpha\left(\mathrm{e}^{\beta \mathrm{V}}-1\right)$ (where $\mathrm{p}$ is pressure, $\mathrm{V}$ is volume and $\alpha$ is a curve-fitting parameter) through the diastolic portion of the pressure-volume loops using a custom MATLAB program [23-25]. Three points (origin $(0,0)$, beginning diastolic point and end-diastolic point) were used for the exponential fit. Eed was obtained from the relationship $\mathrm{dP} / \mathrm{dV}=\alpha \beta \times \mathrm{e}^{\beta \times e n d-d i a s t o l i c}$ volume at calculated end-diastolic volumes $[23,25,26]$. Volume measurements were calibrated with MRI data.

\section{Statistical analyses}

Histograms were visually assessed and the Kolmogorov-Smirnov test was used to determine adherence to a Gaussian distribution. Associations of functional parameters (derived from CPET) with pressure-volume variables and PA parameters were measured with Spearman's rank correlation coefficient; lines show least-squares fits of straight-line models. In addition, Ea and Eed were stratified according to the categories of $V_{\mathrm{E}}^{\prime} / V^{\prime} \mathrm{CO}_{2}$ slope proposed for risk assessment of patients with $\mathrm{PAH}$ in current guidelines [5]. Between-group differences were analysed with the Kruskal-Wallis test or unpaired t-tests as appropriate. For these analyses, $\mathrm{p}<0.05$ was considered statistically significant.

\section{TABLE 1 Clinical characteristics}

Patients with PAH

\begin{tabular}{|c|c|}
\hline Subjects $\mathrm{n}$ & 37 \\
\hline \multicolumn{2}{|l|}{ Sex } \\
\hline Male & 17 \\
\hline Female & 20 \\
\hline Age years & $50 \pm 14$ \\
\hline \multicolumn{2}{|l|}{ PAH subtype } \\
\hline Idiopathic PAH & $31(84)$ \\
\hline Heritable PAH & $2(5)$ \\
\hline PAH associated with & $4(11)$ \\
\hline HIV infection & 1 \\
\hline Connective tissue disease & 3 \\
\hline \multicolumn{2}{|l|}{ Treatment } \\
\hline PDE5i & $16(43)$ \\
\hline ERA & $22(59)$ \\
\hline sGC stimulator & $14(38)$ \\
\hline Prostanoid & $8(22)$ \\
\hline Selexipag & $3(8)$ \\
\hline \multicolumn{2}{|l|}{ Combination therapy } \\
\hline Dual therapy & $10(27)$ \\
\hline Triple therapy & $9(24)$ \\
\hline \multicolumn{2}{|l|}{ WHO functional class $\#$} \\
\hline I & $2(6)$ \\
\hline ॥ & $17(47)$ \\
\hline III & $17(47)$ \\
\hline BNP ${ }^{1} \mathrm{pg} \cdot \mathrm{mL}^{-1}$ & $66(26-177)$ \\
\hline$D_{\text {Lco }} \# \%$ predicted & $61(48-71)$ \\
\hline \multicolumn{2}{|l|}{ Right heart catheterisation } \\
\hline $\mathrm{mPAP} \mathrm{mmHg}$ & $38(34-54)$ \\
\hline $\mathrm{RAP} \mathrm{mmHg}$ & $6 \pm 3$ \\
\hline PVR Wood units & $6.6(4.3-10.4)$ \\
\hline Cardiac index L $\cdot \min ^{-1} \cdot \mathrm{m}^{-2}$ & $2.8 \pm 0.7$ \\
\hline PAWP $\mathrm{mmHg}$ & $9 \pm 3$ \\
\hline
\end{tabular}

Data are presented as $\mathrm{n}(\%)$, mean \pm SD and median (interquartile range), unless otherwise indicated. PAH: pulmonary arterial hypertension; PDE5i: phosphodiesterase type 5 inhibitor; ERA: endothelin receptor antagonist; sGC: soluble guanylate cyclase; WHO: World Health Organization; BNP: B-type natriuretic peptide; $D_{L c 0}$ : diffusion capacity of the lung for carbon monoxide; mPAP: mean pulmonary artery pressure; RAP: right atrial pressure; PVR: pulmonary vascular resistance; PAWP: pulmonary artery wedge pressure. \#: $n=36 ; \uparrow^{\uparrow}: n=35$. 
To determine which pressure-volume loop parameter is most strongly related to ventilatory inefficiency based on the previously recommended prognostically relevant cut-off value of $>48$ for $V_{E}^{\prime} / V^{\prime} \mathrm{CO}_{2}$ slope $[4,27]$, Ea, Ees, Ees/Ea and Eed were included in a univariate logistic binary regression analysis as continuous variables. We then built a multivariate model including BNP, sex, Ea and Eed; multicollinearity was assessed using the variance inflation factor. For the regression analysis, $\mathrm{p}<0.10$ was considered statistically significant.

SPSS version 23.0 (IBM, Armonk, NY, USA) was used for statistical analyses.

\section{Results}

\section{Patients}

In total, 37 patients with PAH were included in the analysis; the majority of the patients (84\%) presented with idiopathic PAH (table 1). A substantial proportion of the patients were already receiving double or

TABLE 2 Right ventricular pressure-volume loop measurements and CPET and MRI-derived parameters

Patients with PAH

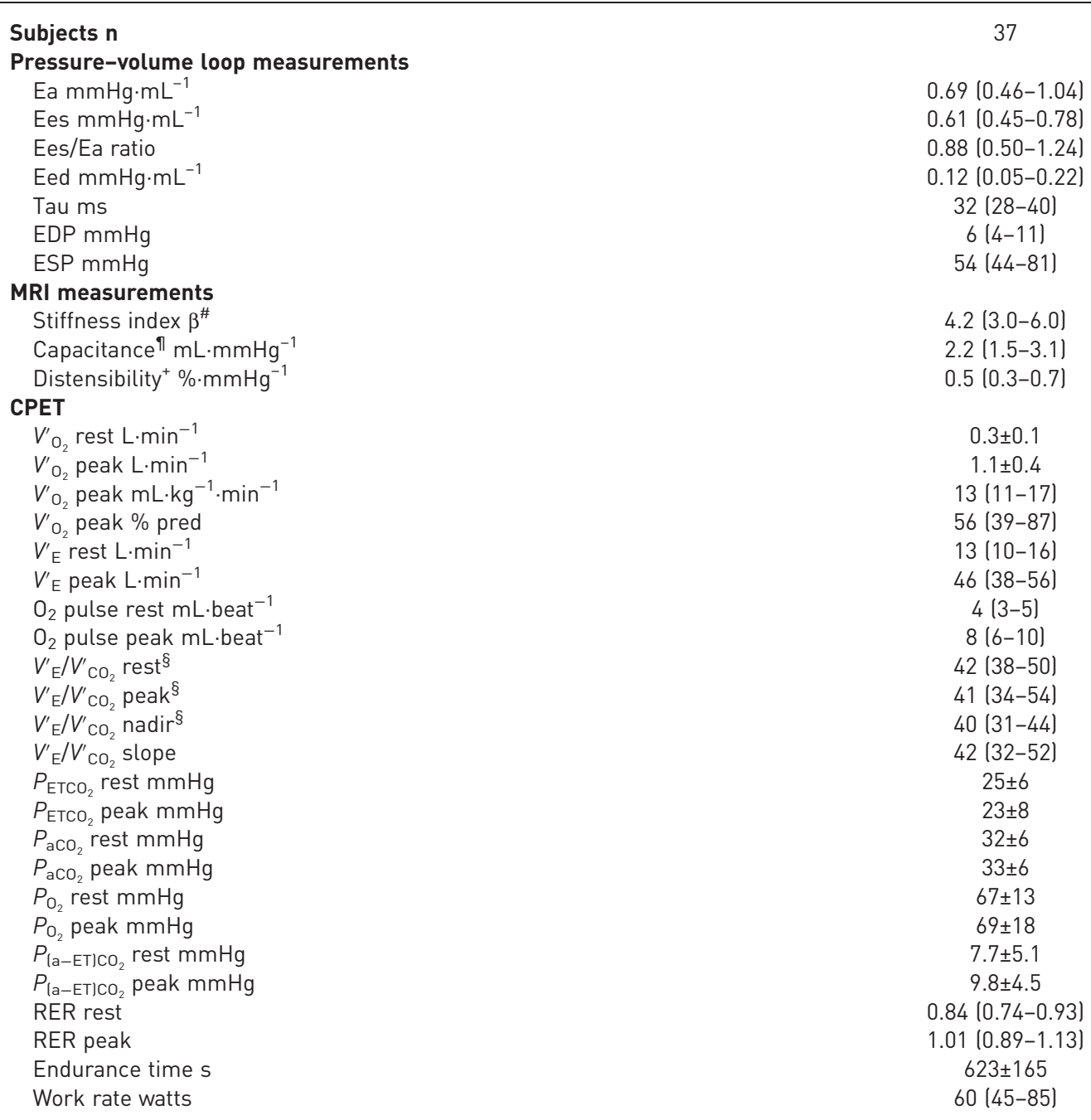

Values represent mean \pm SD or median (interquartile range). $\mathrm{PAH}$ : pulmonary arterial hypertension; Ea: arterial elastance; Ees: end-systolic elastance; Eed: end-diastolic elastance; EDP: end-diastolic pressure; ESP: end-systolic pressure; MRI: magnetic resonance imaging; CPET: cardiopulmonary exercise testing; $V^{\prime}{ }_{\mathrm{O}_{2}}$ : oxygen uptake; $V_{\mathrm{E}}^{\prime}$ : minute ventilation; $V^{\prime}{ }_{\mathrm{E}} / V^{\prime} \mathrm{CO}_{2}$ : minute ventilation/carbon dioxide production (ventilatory equivalent for carbon dioxide); $P_{\mathrm{ETCO}_{2}}$ : end-tidal carbon dioxide tension; $P_{\mathrm{aco}}$ : arterial carbon dioxide tension; $P_{\mathrm{O}_{2}}$ : oxygen tension; $P_{(\mathrm{a}-\mathrm{ET}) \mathrm{CO}_{2}}$ : arterial to end-tidal carbon dioxide tension gradient; RER: respiratory exchange ratio. ${ }^{\#}: n=33 ;{ }^{\uparrow}: n=36 ;{ }^{+}: n=32 ;{ }^{\S}: n=35$. 
triple combinations of drugs targeting the pulmonary circulation, and the majority presented in World Health Organization (WHO) functional classes II or III. Right heart catheterisation measurements showed that the patients had severe, chronic pressure overload. Mean $D_{\mathrm{LCO}}$ was $61 \%$ of predicted. Pressure-volume loop measurements (table 2) showed that the Ees/Ea ratio was lower than the optimal value for RV-PA coupling (1.5-2.0) [15]. MRI measurements revealed a high stiffness index $\beta$ and low capacitance and distensibility in the pulmonary artery. CPET measurements showed an impaired peak work rate with low peak $V_{\mathrm{O}_{2}}^{\prime}$ (in $\mathrm{mL} \cdot \mathrm{min}^{-1} \cdot \mathrm{kg}^{-1}$ and \% predicted) and peak $\mathrm{O}_{2}$ pulse, a high $V_{\mathrm{E}}^{\prime} / V^{\prime} \mathrm{CO}_{2}$ slope and a low $P_{\mathrm{ETCO}_{2}}$ at peak exercise. The $P_{(\mathrm{a}-\mathrm{ET}) \mathrm{CO}_{2}}$ gradient was moderately elevated. Maximum RER slightly exceeded 1 .

\section{Association of CPET parameters with pressure-volume loop-derived measurements of RV function and afterload and MRI-derived measurements of PA stiffness}

The pressure-volume loop-derived parameters $\mathrm{Ea}$ and Eed correlated with $V_{\mathrm{E}}^{\prime} / V^{\prime} \mathrm{CO}_{2}$ slope and peak $P_{\mathrm{ETCO}_{2}}$ (figure 1). In addition, Ea correlated with peak $\mathrm{O}_{2}$ pulse. $V_{\mathrm{E}}^{\prime} / V_{\mathrm{CO}_{2}}^{\prime}$ slope and peak $P_{\mathrm{ETCO}}$ also correlated with PVR (supplementary figure E1). Of note, Eed strongly correlated with resting cardiac index (supplementary figure E2). BNP levels correlated with $\mathrm{Ea}$ and Eed as well as $V_{\mathrm{E}}^{\prime} / V^{\prime} \mathrm{CO}_{2}$ slope and peak $P_{\mathrm{ETCO}_{2}}$ (supplementary figure E3). There were no correlations between Ees/Ea or Ees and CPET parameters (data not shown). There was no correlation between pressure-volume loop-derived measurements and peak $V^{\prime} \mathrm{O}_{2}$. MRI-derived measurements of the stiffness of the pulmonary arteries correlated with $V_{\mathrm{E}}^{\prime} / V^{\prime} \mathrm{CO}_{2}$ slope, peak $P_{\mathrm{ETCO}_{2}}$ and peak $\mathrm{O}_{2}$ pulse (figure 2). $V_{\mathrm{E}}^{\prime} / V^{\prime} \mathrm{CO}_{2}$ nadir showed even more significant correlations with $\mathrm{Ea}$, Eed, stiffness of the pulmonary arteries, PVR and BNP than $V^{\prime}{ }_{\mathrm{E}} / V^{\prime} \mathrm{CO}_{2}$ slope (figure 3).

Eed and Ea were related to $V^{\prime}{ }_{E} / V^{\prime} \mathrm{CO}_{2}$ slope cut-offs proposed for risk assessment of patients with PAH in current guidelines (figure 4) [5].
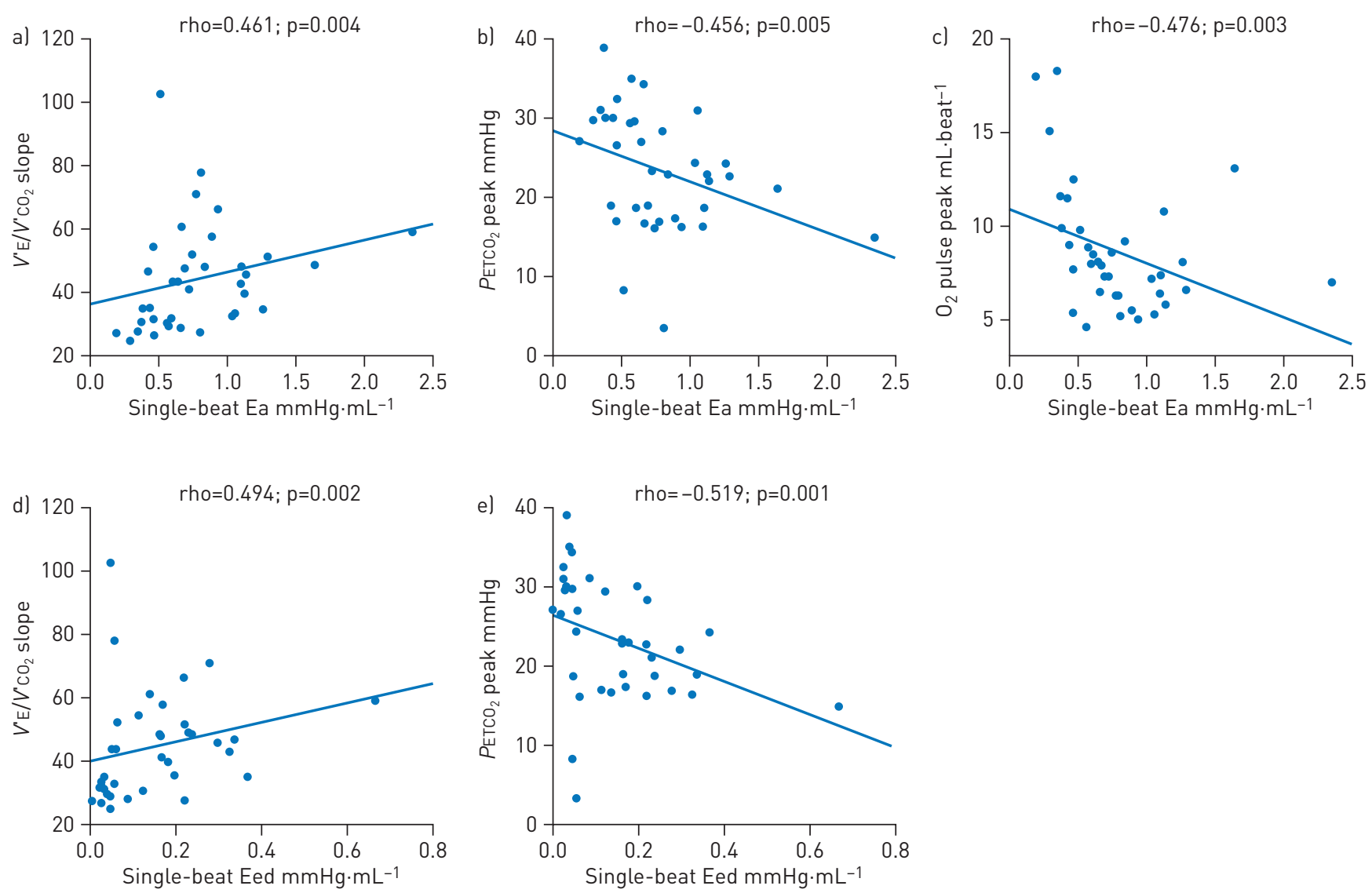

FIGURE 1 Association of cardiopulmonary exercise test parameters with single-beat pressure-volume loop-derived measurements of right ventricular a-c) afterload and d, e) diastolic stiffness. $V_{E}^{\prime} / V^{\prime} \mathrm{CO}_{2}$ : minute ventilation/carbon dioxide production (ventilatory equivalent for carbon dioxide); Ea: arterial elastance; $P_{\mathrm{ETCO}_{2}}$ : end-tidal carbon dioxide tension; Eed: end-diastolic elastance. 

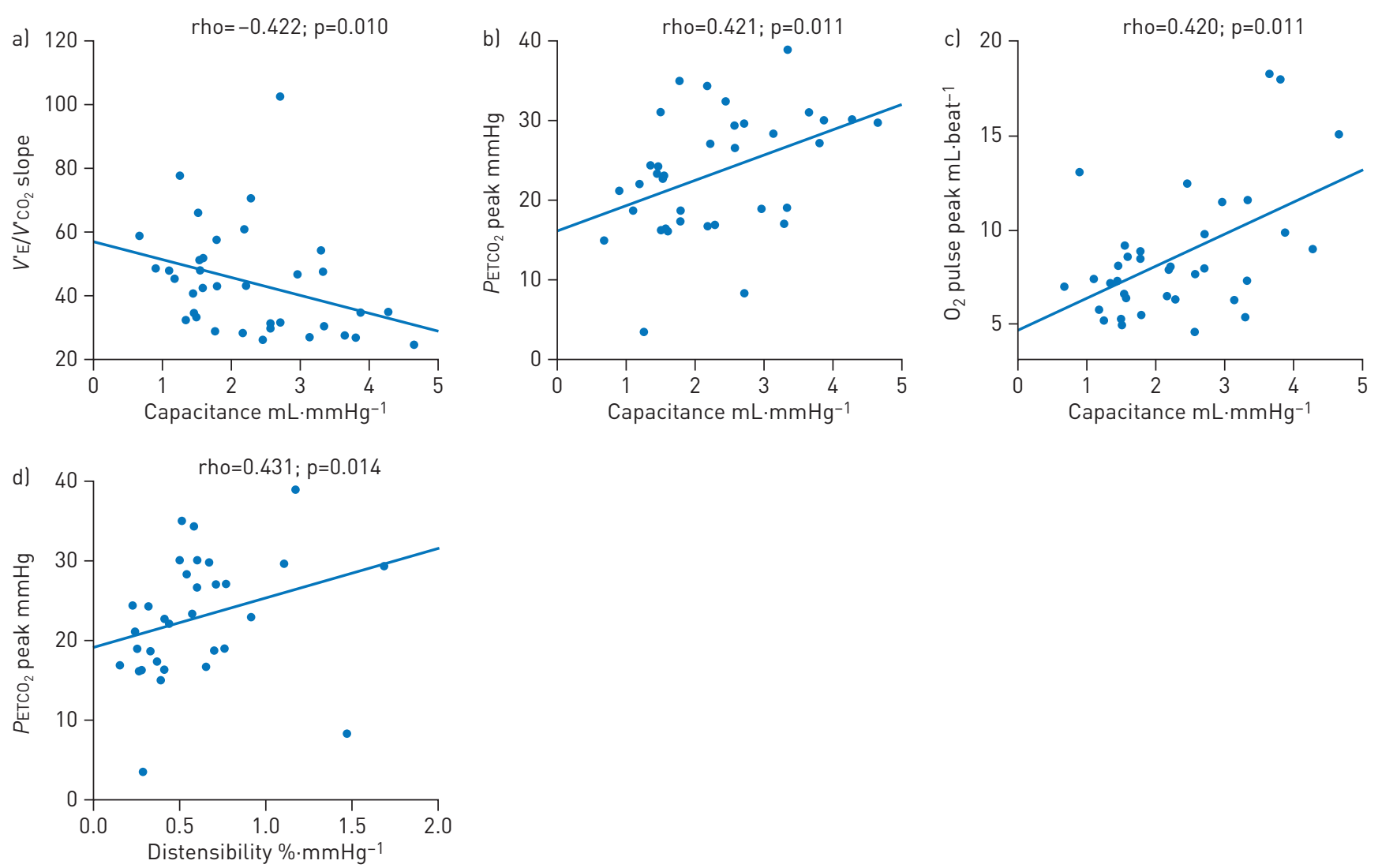

FIGURE 2 Association of cardiopulmonary exercise test parameters with magnetic resonance imaging-derived pulmonary arterial a-c) capacitance and d) distensibility. $V^{\prime} / V^{\prime} \mathrm{CO}_{2}$ : minute ventilation/carbon dioxide production (ventilatory equivalent for carbon dioxide); $P_{\mathrm{E} T \mathrm{CO}_{2}}$ : end-tidal carbon dioxide tension.

Predictive relevance of Ea and Eed for ventilatory inefficiency

In univariate logistic regression analysis, Ea (univariate OR $7.28,95 \%$ CI $1.20-44.04, \mathrm{p}=0.031$ ) and Eed (univariate OR 2.21, 95\% CI 0.93-5.26, $\mathrm{p}=0.073$ ), but not Ees (univariate OR 1.04, $\mathrm{p}=0.955$ ) or Ees/Ea (univariate OR 2.30, $\mathrm{p}=0.129)$, were significantly associated with ventilatory inefficiency $\left(V_{\mathrm{E}}^{\prime} / V^{\prime} \mathrm{CO}_{2}\right.$ slope $>48)$. A model including BNP, sex, Eed and Ea as predictor variables indicated superiority of Ea over Eed (Wald values 3.111 and 0.468 , respectively). Multivariate odds ratios for the association of Ea and Eed with ventilatory inefficiency were 13.16 ( $95 \%$ CI $0.75-230.53, \mathrm{p}=0.078)$ and 1.71 (95\% CI $0.37-7.87$, $\mathrm{p}=0.494$ ), respectively.

\section{Discussion}

In the present study, both diastolic stiffness and increased afterload of the right ventricle were associated with exercise hyperventilation in patients with $\mathrm{PAH}$, while RV contractility (Ees) in isolation or coupled to afterload (Ees/Ea) was not.

Hyperventilation in PAH is caused by a combination of increased dead space ventilation and increased chemosensitivity $[1,2]$. In the present study, the $P_{(\mathrm{a}-\mathrm{ET}) \mathrm{CO}_{2}}$ gradients were only moderately elevated, on average by $2-3 \mathrm{mmHg}$ above the upper limit of normal of $5 \mathrm{mmHg}$ [28], and both $P_{\mathrm{ETCO}_{2}}$ and $P_{\mathrm{aCO}}$ were low, arguing in favour of a dominant role of increased chemosensitivity [29]. Increased ventilatory responses to both hypercapnia and hypoxia have been reported in patients with severe pulmonary hypertension [30]. Consistent with those observations, increased sympathetic nervous system activity has been demonstrated by microneurography in patients with $\mathrm{PAH}$ [31]. Increased sympathetic nervous system activity predicts a poor prognosis in $\mathrm{PAH}$ [32], and an increased $V^{\prime} / V^{\prime} \mathrm{CO}_{2}$ slope has also been identified as a predictor of poor prognosis in PAH, albeit with some variability between PAH subtypes $[3,4]$. The mechanisms of increased chemosensitivity in PAH remain incompletely understood. Atrial septostomy has been reported to decrease sympathetic nervous system tone in $\mathrm{PAH}$, in spite of right-to-left atrial shunt-induced hypoxaemia, which the authors explained by a reverse Bainbridge reflex [33]. Thus, right atrial (and RV) stretch or stiffness could be an important trigger of chemosensitivity and sympathetic nervous system tone in PAH. The increased BNP levels correlating with 

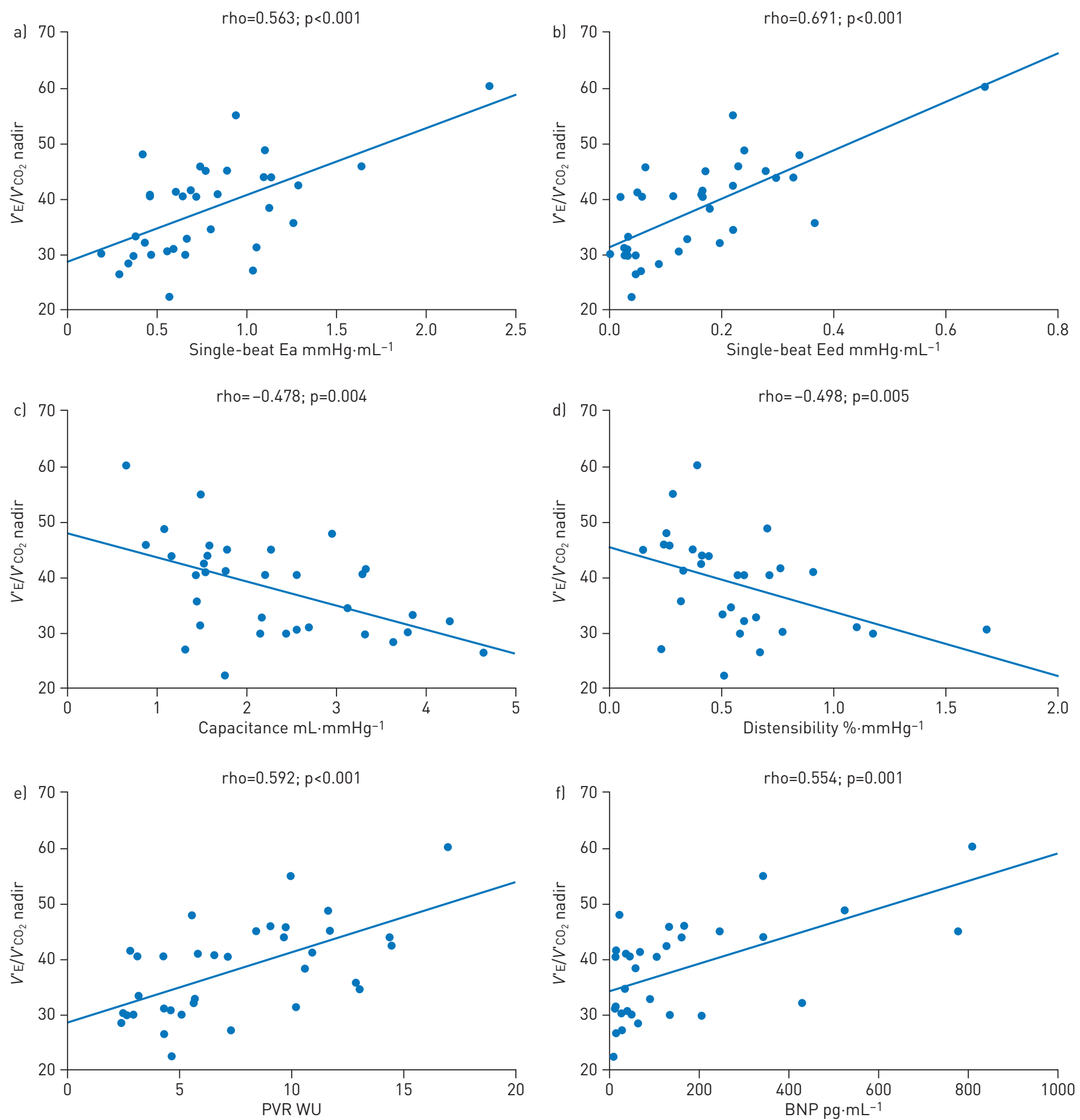

FIGURE 3 Association of $V^{\prime}{ }_{E} / V^{\prime}{ }_{\mathrm{CO}_{2}}$ nadir with a) single-beat arterial elastance (Ea), b) single-beat end-diastolic elastance (Eed), c) capacitance, d) distensibility, e) pulmonary vascular resistance (PVR) and f) B-type natriuretic peptide (BNP). $V^{\prime}{ }_{E} / V^{\prime} \mathrm{CO}_{2}$ : minute ventilation/carbon dioxide production (ventilatory equivalent for carbon dioxide); WU: Wood units.

increased $V_{\mathrm{E}}^{\prime} / V_{\mathrm{CO}_{2}}^{\prime}$ in the present study support this mechanism, as does the observed prediction of ventilatory inefficiency by increased RV diastolic stiffness (Eed) in the presence of increased afterload (Ea). As illustrated in figure 5, plotting of $V_{\mathrm{E}}^{\prime} / V^{\prime} \mathrm{CO}_{2}$ as a function of $P_{\mathrm{aCO}}$ revealed a characteristic leftward shift of the curve (indicative of increased chemosensitivity [34]) in the patients with PAH who also had maladaptive high Eed (based on a previously described cut-off [17]). In addition, $V^{\prime}{ }_{\mathrm{E}} / V^{\prime} \mathrm{CO}_{2}$ was substantially increased at rest and during exercise in patients with high versus low Eed (figure 5b). 

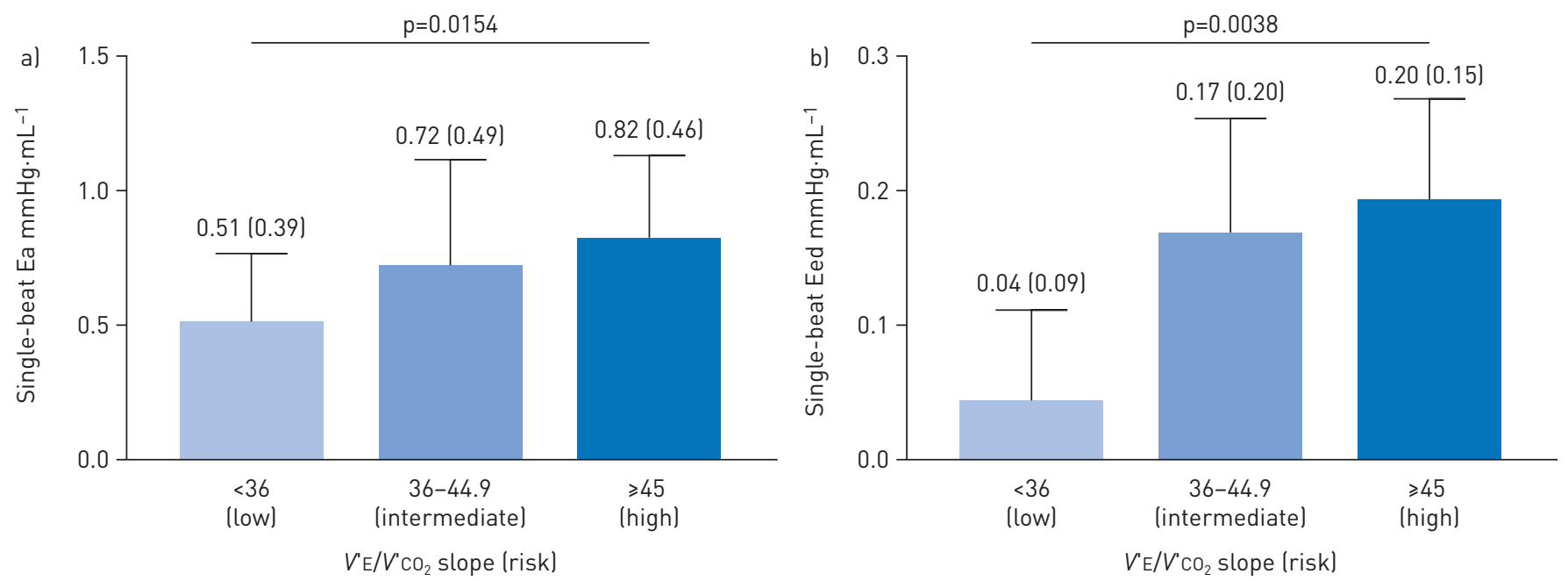

FIGURE 4 a) Afterload and b) right ventricular diastolic stiffness stratified according to the $V^{\prime}{ }_{E} / V^{\prime} \mathrm{Co}_{2}$ slope proposed for risk assessment of patients with pulmonary arterial hypertension in current guidelines [5]. Bar graphs show median and interquartile range. Statistical significance was assessed using the Kruskal-Wallis test. Ea: arterial elastance; $V^{\prime}{ }_{E} / V^{\prime} \mathrm{CO}_{2}$ : minute ventilation/carbon dioxide production (ventilatory equivalent for carbon dioxide); Eed: end-diastolic elastance.

Another possible reflex mechanism would be triggered by PA distension, but this is less convincingly supported by the available evidence. Nevertheless, we found a significant correlation between MRI-derived parameters of PA stiffness and exercise hyperventilation; this might be mediated via the association of these parameters with afterload [12] rather than a direct relationship.

The right ventricle in severe pulmonary hypertension initially adapts by increasing contractility to match the increased afterload [6,7]. This "homeometric adaptation" is assessed by an Ees/Ea ratio determined from pressure-volume loops. When RV-PA coupling deteriorates, reflected by a progressive decrease in Ees/Ea, a "heterometric adaptation" (dimension-dependent) is turned on to preserve cardiac output responses to peripheral demand. This eventually occurs at the price of excessive RV dilatation and systemic congestion. We previously showed that RV-PA coupling in severe PAH has a lot of reserve, because the Ees/Ea ratio needs to decrease from normal values of $1.5-2$ to $<0.8$ before excessive RV dilatation occurs [15]. While RV dilatation is an obvious cause of increased atrial and RV stretch and stiffness, diastolic elastance may also increase out of proportion to systolic elastance in the presence of increased afterload [23]. The present data indirectly support the occurrence of this dissociation because $V_{E}^{\prime} / V^{\prime} \mathrm{CO}_{2}$ increased in association with Eed and Ea. Of note, a further differentiation of Ea and Eed according to the risk stratification cut-offs proposed for the $V_{\mathrm{E}}^{\prime} / V^{\prime} \mathrm{CO}_{2}$ slope in current guidelines [5] showed a distinctive pattern. This sub-differentiation revealed that even patients with an intermediate elevation of $V^{\prime} / V^{\prime} \mathrm{CO}_{2}$ slope [5], and thus ventilatory inefficiency, had a substantial increase in Ea and Eed.

In the present study, RV Ees, Ea and Eed were determined using the single-beat method, which was experimentally validated in animals [22] and thereafter applied to patients with PAH $[15,35,36]$. The alternative would be to derive these measurements using a multiple-beat approach with families of RV pressure-volume loops obtained at decreasing venous return, as was initially reported in isolated heart preparations [37] and later applied to patients with $\mathrm{PAH}[38,39]$. A decrease in venous return can be obtained by inflating a balloon in the inferior vena cava [16] (although this additional invasive procedure may carry some risk and cause ethical concern) or by a Valsalva manoeuvre $[38,39]$. However, it is not known how positive intrathoracic pressures affect RV-PA coupling. Furthermore, decreasing venous return may decrease Ees/Ea because of sympathetic nervous system activation leading to an increase in Ea [22]. On the other hand, the single-beat analysis depends on a maximum RV pressure calculation based on extrapolation of RV pressure curves, which may be technically challenging. Further studies are needed to validate single- and multiple-beat methods against each other. In the meantime, it is conceivable that Ees or Ees/Ea determined by different methods, while being consistent and tending to agree [40], may still differ in terms of correlation to $V^{\prime}{ }_{\mathrm{E}} / V^{\prime} \mathrm{CO}_{2}$. RV Ees and $V_{\mathrm{E}}^{\prime} / V^{\prime} \mathrm{CO}_{2}$ showed a borderline significant correlation $(p=0.049)$ in a multiple-beat study of RV function in a mixed population of patients with systemic sclerosis-associated and idiopathic PAH [38], whereas this correlation did not achieve significance in the present single-beat study of patients with predominantly idiopathic PAH. 
a) Conductance

catheter
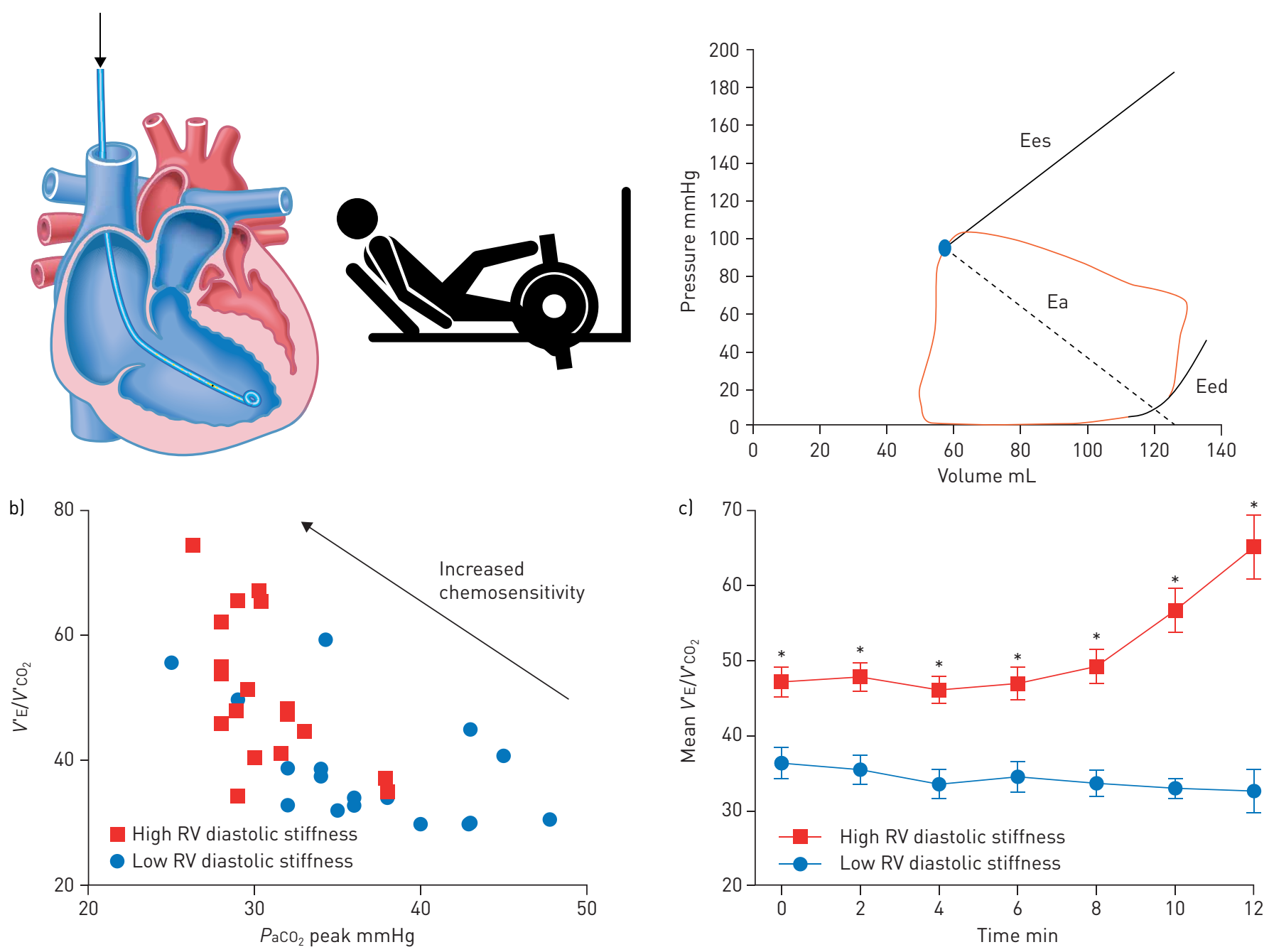

FIGURE 5 Pathophysiological concept of the association of increased diastolic stiffness with increased chemosensitivity in pulmonary arterial hypertension. a) Conductance catheterisation and cardiopulmonary exercise testing allow assessment of right ventricular (RV) diastolic stiffness (end-diastolic elastance (Eed)) and its relationship with chemosensitivity. b) A leftward shift of $V^{\prime}{ }_{E} / V^{\prime} \mathrm{CO}_{2}$ versus arterial carbon dioxide tension $\left(P_{\mathrm{aCO}}\right)$ plots to lower $P_{\mathrm{aCO}}$ and higher $V^{\prime} / V^{\prime} \mathrm{CO}_{2}$ indicates increased chemosensitivity [34], which was found to be present in patients with high RV diastolic stiffness in the current study. c) $V^{\prime}{ }_{E} / V^{\prime} \mathrm{CO}_{2}$ at rest $(0 \mathrm{~min})$ and during symptom-limited incremental cycle exercise (2-12 min) was increased in patients with high versus low RV diastolic stiffness. High RV diastolic stiffness was defined as Eed $>0.124 \mathrm{mmHg} \cdot \mathrm{mL}^{-1}$ as previously described [17]. Error bars show standard error of the mean. ${ }^{*}: p<0.01$ (between-group differences analysed with unpaired t-test). Ea: arterial elastance; $V^{\prime}{ }_{E} / V^{\prime} \mathrm{CO}_{2}$ : minute ventilation/carbon dioxide production (ventilatory equivalent for carbon dioxide).

The ventilatory response to exercise is usually assessed by the slope of $V_{\mathrm{E}}^{\prime}$ as a function of $V^{\prime} \mathrm{CO}_{2}$. Although studies of the prognostic role of the $V^{\prime}{ }_{E} / V^{\prime} \mathrm{CO}_{2}$ slope have produced variable results in PAH $[3,4,41,42]$, the $V_{\mathrm{E}}^{\prime} / V^{\prime} \mathrm{CO}_{2}$ slope has been identified as an important and potent predictor of outcome in left-sided heart failure [43, 44] and PAH [3, 4, 27], and has been reported to be associated with afterload (assessed as PVR) in heart failure with preserved ejection fraction [9]. It has been argued that the slope of $V_{E}^{\prime} / V^{\prime} \mathrm{CO}_{2}$ would be better replaced by its nadir as being a less effort-dependent and more stable measurement [20]. In the present study, the nadir of $V^{\prime}{ }_{\mathrm{E}} / V^{\prime} \mathrm{CO}_{2}$ actually showed a better correlation with $\mathrm{RV}$ diastolic stiffness and afterload than did the slope of $V^{\prime}{ }_{E} / V^{\prime} \mathrm{CO}_{2}$. However, $V_{E}^{\prime} / V^{\prime} \mathrm{CO}_{2}$ to predict outcome in PAH or left-sided heart failure is usually reported as slope instead of nadir.

In addition, echocardiographic measurements of RV dimensions and systolic function have been shown to be related to ventilatory inefficiency in patients with severe left heart failure [10], in keeping with the notion of increased chemosensitivity secondary to increased RV stretch and stiffness. Whether a right heart phenotype might worsen wasted ventilation and associated dyspnoea in heart failure remains to be clarified. 
There is more to shortness of breath in PAH than wasted ventilation. Recent studies have suggested a significant contribution of dynamic hyperinflation during exercise in these patients $[45,46]$. Even though this mechanism is not a cause of ventilatory limitation to aerobic exercise and is not related to respiratory muscle weakness in PAH [47], it contributes to exercise intolerance by worsening dyspnoea at any level of workload. However, the extent to which hyperventilation, dead space ventilation, chemosensitivity and/or the abnormal response of the pulmonary circulation during exercise contribute to excessive dynamic hyperinflation is currently unknown.

The patients with PAH included in the present study were severely ill, with about half in WHO functional class III and most of the others in WHO functional class II (the remaining two patients were in WHO functional class I). However, they are representative of patients with $\mathrm{PAH}$ admitted and followed in pulmonary hypertension referral centres. In a review of $11 \mathrm{PAH}$ registries, McGoon et al. [48] reported that $54 \%-80 \%$ of the patients were in WHO functional classes III/IV; previous PAH registry populations were thus even more severely ill than our cohort. The peak $V^{\prime} \mathrm{O}_{2}$ and workload values in the present study were typical for patients with PAH [4, 27, 42, 49], and similar to those reported in multiple-beat RV function studies [38]. It cannot be excluded that clustering of Ees at a very low range of values prevented the uncovering of significant correlations with $V_{\mathrm{E}}^{\prime} / V^{\prime} \mathrm{CO}_{2}$.

\section{Limitations}

We compared pressure-volume parameters at rest with parameters assessed under exercise (CPET). The analysis is thus limited by the fact that pressure-volume loops were not generated during exercise. We performed a single-beat analysis of pressure-volume loops, and it is unclear if the multiple-beat approach would produce similar results. The prognostic $V^{\prime}{ }_{E} / V^{\prime} \mathrm{CO}_{2}$ cut-off value of 48 relied mainly on the study by Groepenhoff and co-workers [4, 27] and may thus not be sufficiently robust [3]. The small size, the relatively low RER and the advanced functional status of our study population may also have biased our results. Nevertheless, we believe the sample size is reasonable for a study of invasive pressure-volume catheterisation in patients with PAH, and submaximal exercise testing yielding a RER $<0.9$ in PAH did not affect key ventilatory parameters [50]. The small sample size limited the univariate and multivariate logistic regression analyses and prevented further in-depth or receiver operating characteristic analysis. In addition, data-driven cut-offs, especially in small sample sizes, should be interpreted with caution and need external validation. Finally, it has to be underscored that showing independent prediction of $V^{\prime} / V^{\prime} \mathrm{CO}_{2}$ by $\mathrm{RV}$ Eed and $\mathrm{Ea}$ does not prove causation, which needs to be further investigated by dedicated studies.

\section{Conclusion}

Our data suggest that both impaired RV lusitropy and increased RV afterload are associated with ventilatory inefficiency in PAH. The potential implications of this finding for PAH treatment warrant further study.

Acknowledgements: We thank Claire Mulligan (Beacon Medical Communications Ltd, Brighton, UK) for editorial support, funded by the University of Giessen.

Support statement: Funded by the Deutsche Forschungsgemeinschaft (DFG, German Research Foundation) Projektnummer 268555672 - SFB 1213, Project B08. Funding information for this article has been deposited with the Crossref Funder Registry.

Conflict of interest: K. Tello reports that this work was funded by the Excellence Cluster Cardio-Pulmonary System (ECCPS) and the Collaborative Research Center (SFB) 1213 - Pulmonary Hypertension and Cor Pulmonale, grant number SFB1213/1, project B08 (grant from German Research Foundation, Bonn, Germany) and editorial support was funded by University of Giessen, during the conduct of the study; and personal fees for lectures from Actelion and Bayer, outside the submitted work. A. Dalmer has nothing to disclose. R. Vanderpool has nothing to disclose. H.A. Ghofrani reports that this work was funded by the ECCPS and the Collaborative Research Center (SFB) 1213 Pulmonary Hypertension and Cor Pulmonale, grant number SFB1213/1, project B08 (grant from German Research Foundation, Bonn, Germany) and editorial support was funded by University of Giessen, during the conduct of the study; and personal fees for consultancy and advisory board work from Bayer and Pfizer, personal fees for consultancy, lectures and advisory board work from Actelion and GSK, personal fees for consultancy from Merck, grants and personal fees for consultancy from Novartis, grants and personal fees for lectures from Bayer HealthCare and Encysive/ Pfizer, grants from Aires, German Research Foundation, Excellence Cluster Cardiopulmonary Research and German Ministry for Education and Research, and personal fees for advisory board work from Takeda, outside the submitted work. R. Naeije reports grants and personal fees for consultancy and advisory board work from AOP Orphan Pharmaceuticals, Actelion, Bayer, Reata, Lung Biotechnology Corporation and United Therapeutics, outside the submitted work. F. Roller has nothing to disclose. W. Seeger reports that this work was funded by the ECCPS and the Collaborative Research Center (SFB) 1213 - Pulmonary Hypertension and Cor Pulmonale, grant number SFB1213/1, project B08 (grant from German Research Foundation, Bonn, Germany) and editorial support was funded by University of Giessen, during the conduct of the study; and personal fees for consultancy and lectures from Pfizer and Bayer Pharma AG, outside the submitted work. D. Dumitrescu reports personal fees and advisory board membership from 
Actelion and Novartis, and personal fees from Bayer Healthcare, GSK, MSD and Servier, outside the submitted work. N. Sommer reports personal fees from Actelion, outside the submitted work. A. Brunst has nothing to disclose. H. Gall reports that this work was funded by the ECCPS and the Collaborative Research Center (SFB) 1213 - Pulmonary Hypertension and Cor Pulmonale, grant number SFB1213/1, project B08 (grant from German Research Foundation, Bonn, Germany) and editorial support was funded by University of Giessen, during the conduct of the study; and personal fees from Actelion, AstraZeneca, Bayer, BMS, GSK, Janssen-Cilag, Lilly, MSD, Novartis, OMT, Pfizer and United Therapeutics, outside the submitted work. M.J. Richter reports that this work was funded by the ECCPS and the Collaborative Research Center (SFB) 1213 - Pulmonary Hypertension and Cor Pulmonale, grant number SFB1213/1, project B08 (grant from German Research Foundation, Bonn, Germany) and editorial support was funded by University of Giessen, during the conduct of the study; and grants from United Therapeutics, grants and personal fees for consultancy and lectures from Bayer, and personal fees for lectures from Actelion, Mundipharma, Roche and OMT, outside the submitted work.

\section{References}

1 Weatherald J, Sattler C, Garcia G, et al. Ventilatory response to exercise in cardiopulmonary disease: the role of chemosensitivity and dead space. Eur Respir J 2018; 51: 1700860.

2 Dumitrescu D, Sitbon O, Weatherald J, et al. Exertional dyspnoea in pulmonary arterial hypertension. Eur Respir Rev 2017; 26: 170039.

3 Deboeck G, Scoditti C, Huez S, et al. Exercise testing to predict outcome in idiopathic versus associated pulmonary arterial hypertension. Eur Respir J 2012; 40: 1410-1419.

4 Groepenhoff $\mathrm{H}$, Vonk-Noordegraaf A, Boonstra A, et al. Exercise testing to estimate survival in pulmonary hypertension. Med Sci Sports Exerc 2008; 40: 1725-1732.

5 Galie N, Humbert M, Vachiery JL, et al. 2015 ESC/ERS guidelines for the diagnosis and treatment of pulmonary hypertension. Eur Respir J 2015; 46: 903-975.

6 Vonk Noordegraaf A, Chin KM, Haddad F, et al. Pathophysiology of the right ventricle and of the pulmonary circulation in pulmonary hypertension: an update. Eur Respir J 2019; 53: 1801900.

7 Vonk Noordegraaf A, Westerhof BE, Westerhof N. The relationship between the right ventricle and its load in pulmonary hypertension. J Am Coll Cardiol 2017; 69: 236-243.

8 Naeije R, Manes A. The right ventricle in pulmonary arterial hypertension. Eur Respir Rev 2014; 23: 476-487.

9 Klaassen SHC, Liu LCY, Hummel YM, et al. Clinical and hemodynamic correlates and prognostic value of VE/ $\mathrm{VCO}_{2}$ slope in patients with heart failure with preserved ejection fraction and pulmonary hypertension. $J$ Card Fail 2017; 23: 777-782.

10 Methvin AB, Owens AT, Emmi AG, et al. Ventilatory inefficiency reflects right ventricular dysfunction in systolic heart failure. Chest 2011; 139: 617-625.

11 Farina S, Correale M, Bruno N, et al. "Right and Left Heart Failure Study Group" of the Italian Society of Cardiology. The role of cardiopulmonary exercise tests in pulmonary arterial hypertension. Eur Respir Rev 2018; 27: 170134

12 Sanz J, Kariisa M, Dellegrottaglie S, et al. Evaluation of pulmonary artery stiffness in pulmonary hypertension with cardiac magnetic resonance. JACC Cardiovasc Imaging 2009; 2: 286-295.

13 Gall H, Felix JF, Schneck FK, et al. The Giessen Pulmonary Hypertension Registry: survival in pulmonary hypertension subgroups. J Heart Lung Transplant 2017; 36: 957-967.

14 Tello K, Richter MJ, Axmann J, et al. More on single-beat estimation of right ventriculoarterial coupling in pulmonary arterial hypertension. Am J Respir Crit Care Med 2018; 198: 816-818.

15 Tello K, Dalmer A, Axmann J, et al. Reserve of right ventricular-arterial coupling in the setting of chronic overload. Circ Heart Fail 2019; 12: e005512.

16 Tello K, Dalmer A, Husain-Syed F, et al. Multi-beat right ventricular-arterial coupling during a positive acute vaso-reactivity test. Am J Respir Crit Care Med 2019; 199: e41-e42.

17 Tello K, Dalmer A, Vanderpool R, et al. Cardiac magnetic resonance imaging-based right ventricular strain analysis for assessment of coupling and diastolic function in pulmonary hypertension. JACC Cardiovasc Imaging 2019; 12: 2155-2164.

18 Macintyre N, Crapo RO, Viegi G, et al. Standardisation of the single-breath determination of carbon monoxide uptake in the lung. Eur Respir J 2005; 26: 720-735.

19 Scheidl SJ, Englisch C, Kovacs G, et al. Diagnosis of CTEPH versus IPAH using capillary to end-tidal carbon dioxide gradients. Eur Respir J 2012; 39: 119-124

20 Wasserman K, Hansen JE, Sue DY, et al. Principles of Exercise Testing and Interpretation. 5th Edn. Philadelphia, Lippincott Williams \& Wilkins, 2011.

21 Tello K, Axmann J, Ghofrani HA, et al. Relevance of the TAPSE/PASP ratio in pulmonary arterial hypertension. Int J Cardiol 2018; 266: 229-235.

22 Brimioulle S, Wauthy P, Ewalenko P, et al. Single-beat estimation of right ventricular end-systolic pressure-volume relationship. Am J Physiol Heart Circ Physiol 2003; 284: H1625-H1630.

23 Rain S, Handoko ML, Trip P, et al. Right ventricular diastolic impairment in patients with pulmonary arterial hypertension. Circulation 2013; 128: 2016-2025.

24 Vanderpool RR, Pinsky MR, Naeije R, et al. RV-pulmonary arterial coupling predicts outcome in patients referred for pulmonary hypertension. Heart 2015; 101: 37-43.

25 Vanderpool RR, Puri R, Osorio A, et al. EXPRESS: surfing the right ventricular pressure waveform: methods to assess global, systolic and diastolic RV function from a clinical right heart catheterization. Pulm Circ 2019; in press [https://doi.org/10.1177/2045894019850993].

26 Trip P, Rain S, Handoko ML, et al. Clinical relevance of right ventricular diastolic stiffness in pulmonary hypertension. Eur Respir J 2015; 45: 1603-1612.

27 Groepenhoff H, Vonk-Noordegraaf A, van de Veerdonk MC, et al. Prognostic relevance of changes in exercise test variables in pulmonary arterial hypertension. PLoS One 2013; 8: e72013.

28 Robin ED, Forkner CE Jr., Bromberg PA, et al. Alveolar gas exchange in clinical pulmonary embolism. $N$ Engl $J$ Med 1960; 262: 283-287.

29 Naeije R, Faoro V. The breathlessness of pulmonary hypertension. Int J Cardiol 2018; 259: 183-184. 

thromboembolic pulmonary hypertension. Int J Cardiol 2018; 259: 178-182.

31 Velez-Roa S, Ciarka A, Najem B, et al. Increased sympathetic nerve activity in pulmonary artery hypertension. Circulation 2004; 110: 1308-1312.

32 Ciarka A, Doan V, Velez-Roa S, et al. Prognostic significance of sympathetic nervous system activation in pulmonary arterial hypertension. Am J Respir Crit Care Med 2010; 181: 1269-1275.

33 Ciarka A, Vachiery JL, Houssiere A, et al. Atrial septostomy decreases sympathetic overactivity in pulmonary arterial hypertension. Chest 2007; 131: 1831-1837.

34 Naeije R, Faoro V. The great breathlessness of cardiopulmonary diseases. Eur Respir J 2018; $51: 1702517$.

35 Kuehne T, Yilmaz S, Steendijk P, et al. Magnetic resonance imaging analysis of right ventricular pressure-volume loops: in vivo validation and clinical application in patients with pulmonary hypertension. Circulation 2004; 110: 2010-2016.

36 Spruijt OA, de Man FS, Groepenhoff $\mathrm{H}$, et al. The effects of exercise on right ventricular contractility and right ventricular-arterial coupling in pulmonary hypertension. Am J Respir Crit Care Med 2015; 191: 1050-1057.

37 Maughan WL, Shoukas AA, Sagawa K, et al. Instantaneous pressure-volume relationship of the canine right ventricle. Circ Res 1979; 44: 309-315.

38 Hsu S, Houston BA, Tampakakis E, et al. Right ventricular functional reserve in pulmonary arterial hypertension. Circulation 2016; 133: 2413-2422.

39 Tedford RJ, Mudd JO, Girgis RE, et al. Right ventricular dysfunction in systemic sclerosis-associated pulmonary arterial hypertension. Circ Heart Fail 2013; 6: 953-963.

40 Inuzuka R, Hsu S, Tedford RJ, et al. Single-beat estimation of right ventricular contractility and its coupling to pulmonary arterial load in patients with pulmonary hypertension. J Am Heart Assoc 2018; 7: e007929.

41 Wensel R, Francis DP, Meyer FJ, et al. Incremental prognostic value of cardiopulmonary exercise testing and resting haemodynamics in pulmonary arterial hypertension. Int J Cardiol 2013; 167: 1193-1198.

42 Wensel R, Opitz CF, Anker SD, et al. Assessment of survival in patients with primary pulmonary hypertension: importance of cardiopulmonary exercise testing. Circulation 2002; 106: 319-324.

43 Francis DP, Shamim W, Davies LC, et al. Cardiopulmonary exercise testing for prognosis in chronic heart failure: continuous and independent prognostic value from $\mathrm{VE} / \mathrm{VCO}_{2}$ slope and peak $\mathrm{VO}_{2}$. Eur Heart J 2000; 21: $154-161$.

44 Sue DY. Excess ventilation during exercise and prognosis in chronic heart failure. Am J Respir Crit Care Med 2011; 183: $1302-1310$.

45 Richter MJ, Voswinckel R, Tiede H, et al. Dynamic hyperinflation during exercise in patients with precapillary pulmonary hypertension. Respir Med 2012; 106: 308-313.

46 Laveneziana P, Garcia G, Joureau B, et al. Dynamic respiratory mechanics and exertional dyspnoea in pulmonary arterial hypertension. Eur Respir J 2013; 41: 578-587.

47 Laveneziana P, Humbert M, Godinas L, et al. Inspiratory muscle function, dynamic hyperinflation and exertional dyspnoea in pulmonary arterial hypertension. Eur Respir J 2015; 45: 1495-1498.

48 McGoon MD, Benza RL, Escribano-Subias P, et al. Pulmonary arterial hypertension: epidemiology and registries. J Am Coll Cardiol 2013; 62: D51-D59.

49 Deboeck G, Niset G, Lamotte M, et al. Exercise testing in pulmonary arterial hypertension and in chronic heart failure. Eur Respir J 2004; 23: 747-751.

50 Woods PR, Frantz RP, Taylor BJ, et al. The usefulness of submaximal exercise gas exchange to define pulmonary arterial hypertension. J Heart Lung Transplant 2011; 30: 1133-1142. 